\title{
MÚSICA Y SENSACIÓN SONORA: JOHN TAVENER ${ }^{1}$
}

\author{
POR \\ Boris Alvarado \\ Pontificia Universidad Católica de Valparaíso, Chile \\ RicARDo EsPINOZA LOLAS \\ Pontificia Universidad Católica de Valparaíso, Chile \\ Patricio Landaeta Mardones \\ Universidad de la Playa Ancha, Chile
}

\section{RESUMEN}

Lo que busca este artículo es investigar el bello y difícil acto de la sensación sonora de la obra de John Tavener (1944-2013) a la luz de una lógica de la sensación de Gilles Deleuze (1925-1995) y de la fenomenología del cuerpo de Xavie Zubiri (1898-1983). Creemos que con los conceptos acuñados por ambos filósofos pueden dar cuenta de un modo más acabado de ese estilo único de la experiencia sonora en la vibración que propone el arte sacro de la música minimal del compositor anglosajón.

PalABRAS ClAVES: Tavener, Deleuze, Zubiri, Sensación, Minimalismo,Sonido, Vibración

\section{MUSIC AND SOUND SENSATION: JOHN TAVENER}

\begin{abstract}
This article aims to examine the act of sound sensation in John Tavener Work (1944-2013) following the idea of logic of sensation created by Gilles Deleuze (1925-1995) and phenomenology of the body Xavie Zubiri (1898-1983). Through the concepts of from both philosophers it might be possible to draw the sound experience of vibration that proposes the sacred art of minimalism in the AngloSaxon composer.
\end{abstract}

\footnotetext{
${ }^{1}$ Este artículo es parte del Proyecto Fondecyt Realidad y cuerpo en Zubiri (Proyecto No: 1110507).
} 
KEY WORDS: Tavener, Deleuze, Zubiri, Sensation, Minimalism, sound, vibration

\author{
Recibido/Received 29-01-2013 \\ Aceptado/Accepted 03-04-2014
}

\title{
INTRODUCCIÓN
}

«No pienso que sea una cosa extraña ser un músico sacro en el atardecer del siglo $\mathrm{xx}$, lo que pienso que es extraño es el siglo Xx, pienso que el atardecer del siglo Xx es anormal. Quizá, nunca entendamos verdaderamente lo que es la Cristiandad. Cuando miro la música occidental, sé que tengo un pedazo de ella, pero cuando la miro realmente la veo más pequeña de cualquiera de las cualidades de la Cristiandad, y particularmente las cualidades de las Beatitudes, que son pobreza de espíritu y pureza de corazón. Son muy difíciles de encontrar hoy en día en medio de la música» (Tavener y Keeble, The music of silence: a composer's testament).

¿Qué hay en la música sacra contemporánea que no nos deja indiferente y nos estremece, y nos hace sentir de un modo distinto cierta trascendencia? ¿Por qué la música sacra nos invita a vivir la experiencia del sonido y en tal experiencia a poder elevarnos por encima de nuestra cotidianidad inmanente? ¿Qué se da en este tipo de música, en general, y en la de John Tavener, en especial, que es imposible dejar de escuchar, incluso más allá de si se tiene o no fe? Creemos que una respuesta posible es que en esta música se da el «acontecimiento» del elemento sonoro en toda su radicalidad. Y por ello necesitamos, por una parte, de una lógica de la sensación sonora (Deleuze) ${ }^{2}$ y, por otra parte, de una fenomenología del cuerpo (Zubiri) que nos permitan dar cuenta de ese atemperamiento ${ }^{3}$ a las sensaciones; a ese acomplamiento a las ondas rítmicas del sonido. Una

${ }^{2}$ «Poner en variación continua elementos cualesquiera en una operación que quizá hará surgir nuevas distinciones, pero que no conserva ninguna como definitiva, como tampoco se da ninguna de antemano. Al contario, en principio esta operación tiene que ver a la vez con la voz, la palabra, la lengua, la música. No hay ninguna razón para hacer distinciones previas y de principio. En general, la lingüística todavía no ha abandonado una especie de modo mayor, una especie de escala diatónica, un extraño gusto por las dominantes, las constantes y los universales. Entre tanto, todas las lenguas están en variación continua inmanente. Ni sincronía ni diacronía, sino asincronía, cromatismo como estado variable y continuo de la lengua». Esto es una lógica de la sensación. (Deleuze G.; Guattari F. 2000. Mil Mesetas. Capitalismo y esquizofrenia: 100-101. Valencia: Pre-textos).

${ }^{3}$ «Atemperamiento no significa un hombre atemperado, ni significa aquí solamente estar moderado, ser comedido en sus reacciones, sino que, como dice el diccionario a propósito de atemperar, consiste en 'acomodar una cosa a otra'. Pues bien, el modo de estar acomodado tónicamente a la realidad es aquello en que consiste formalmente el sentimiento. En mi opinión, la esencia formal del sentimiento es ser atemperamiento a la realidad». (Zubiri, X. 2002. Sobre el sentimiento y la volición: 335. Madrid: Alianza).

Hispania Sacra, LXVI

134, julio-diciembre 2014, 767-784, ISSN: 0018-215X, doi: 10.3989/hs.2014.068 
lógica que se mantiene en torno a un cuerpo (sensaciones) que está siendo en el mundo y que no busca teorizar sobre el sonido, sino describirlo en su propio registro sonoro (como por de dentro). Tal lógica (técnica) genera una cartografía de la sensación y en tal cartografiar podemos detenernos en la sensación sonora y allí quedarnos en la vibración. En estos elementos radica, creemos, eso que nos cautiva, nos seduce y nos transforma de la música. El sonido en toda su expresión se agencia de un modo sensitivo en la música de Tavener.

En el llamado minimalismo sacro contemporánea, hay muchos compositores de gran importancia, que provienen incluso de países en donde lo sacro no formó parte de la tradición, particularmente en países de la antigua red de países socialistas. Junto a John Tavener (1944) en Inglaterra cuya orientación ortodoxa griega es ampliamente conocida, por ejemplo, también podemos pensar en Henryk Mikolaj Gorecki (1933-2010) en Polonia, en Arvo Pärt (1935) en Estonia, Peteris Vasks (1946) en Latvia y Victoria Poleva (1962) en Ucrania, pero creemos que es en Tavener donde se da realmente una experiencia de la sensación sonora de la vibración como aquellos antiguos isones griegos, una experiencia sonora que mienta en sí misma, una cierta ontología del cuerpo como de la sensación en tanto que sonora, esto es, en el fondo se mienta, una realidad sonora.

Por lo complejo del estudio propuesto en torno a Tavener y la sensación sonora estaremos pensando desde dos obras fundamentales de dos filósofos europeos contemporáneos y sus obras son de años de publicación similar. Una es de Xavier Zubiri y se trata de Inteligencia sentiente y otra es de Gilles Deleuze titulada Francis Bacon. Lógica de la sensación. Son obras que abren un horizonte común a la sensación y al cuerpo; y nos permitirán sumergirnos de modo más acabado en la obra musical de Tavener y entender así su técnica única de composición.

Hemos preferido trabajar con el libro de Deleuze: Francis Bacon. Lógica de la sensación (1981) porque creemos que, por una parte, es un excelente trabajo sobre la sensación (en tanto que pintura) y, por otra parte, porque es un libro único, brillante, filosóficamente «encarnado» en el Cuerpo, por medio de la sensación del ver (también la del oír, tocar, etc.), pero no de un ver abstracto, neutral, fenomenológico (donde queda reducido lo físico), sino, como diría Deleuze, del ver la pintura, de un Ojo «ante» la Figura, ante un cuadro de Bacon o de Goya; un ver más en el sentido fuerte y físico que en un análisis fenomenológico de Merleau-Ponty y que nosotros lo llevaremos al oír, a la sensación física del oír, por eso intentaremos pensar una lógica de la sensación física sonora.

Como se sabe, siguiendo a Deleuze, ante un determinado y propio cuadro de Francis Bacon acontece la experiencia sensitiva de ver, del Ojo que ve la Figura (toda Figura tiene el carácter de Icono, al igual que la obra de Tavener, ya 
volveremos sobre esto), de la Figura que se deja ver ante el Ojo, de la relaciónexperiencia sensitiva Ojo-Figura (es el estar-en-el-mundo de los fenomenólogos pero de manera física sin dejar nada fuera del análisis); ${ }^{4}$ y en tal experiencia damos con el cuerpo, pero un «cuerpo sin órganos» (Deleuze) y en ello con una cierta y provisoria presentación de la realidad que luego se vuelve por construcción en sentido y después en lenguaje, teoría, etc. Deleuze lo señala bellamente así al hablar de la pintura:

La pintura es histeria, o sustituye a la histeria, porque da a ver la presencia, directamente. Gracias a los colores y a las líneas, inviste el ojo. Pero ella, al ojo, no lo trata como un órgano fijo. Liberando a las líneas y a los colores de la representación, libera al mismo tiempo al ojo de su pertenencia al organismo, lo libera de su carácter de órgano fijo y cualificado: el ojo se convierte virtualmente en el órgano indeterminado polivalente, que ve el cuerpo sin órganos, es decir, la Figura, como pura presencia. La pintura nos pone ojos en todas partes: en el oído, en el vientre, en los pulmones. ${ }^{5}$

Nosotros creemos que en este pasaje hay claves hermenéuticas determinantes que pueden ser usadas tanto para el sonido como para la música. Puesto que se indica el acontecimiento mismo de la sensación que en verdad está articulada a la vez con el mundo en una unidad superior física.

Para el compositor inglés Sir John Tavener, nacido en 1945 y muerto en el 2013, la música es un medio de alabanza al Creador (un dios que no tiene rasgos metafísicos sino rasgos sonoros y que acontece al hombre en su ser auditivo), y así lo ha manifestado a lo largo de su extensa obra y, además, desde su ser ortodoxo esa música está impregnada desde sonoridades griegas que la vuelven más luminosa; de allí su carácter Figural o de Icono, porque es una Figura situada a un cierto territorio (en un plano de inmanencia codificado) y por tanto se vuelve en imagen, se actualiza a la luz de su territorialidad sensitiva: «La relación de la Figura con su lugar aislante define un hecho: el hecho es... eso que tiene lugar...

${ }^{4}$ «Para Zubiri, la fenomenología dio un paso muy importante en el estudio, sin teorizar (lo mismo piensa Heidegger), del hecho mismo dado en la aprehensión, pero se quedó, en el fondo, muy pobre en su descripción porque radicalmente nunca fue una descripción 'física' del hecho mismo de la aprehensión; la fenomenología quedó atrapada en la inteligencia concipiente... Pues, lo que sucedía con la fenomenología era que se escondía en ella un rasgo fundamental de la inteligencia concipiente: la dualidad entre sentir e inteligir. De ahí la reducción trascendental de la fenomenología, reducción que nos permite dar con el sub-jectum neutrum por antonomasia de un modo intencional y no físico». (Espinoza R.; Nicolás, J. 2008. Zubiri ante Heidegger: 225-226. Barcelona: Herder).

${ }^{5}$ Deleuze, G. 2002. Francis Bacon. Lógica de la sensación: 58-59. Madrid: Arena Libros.

Hispania Sacra, LXVI

134, julio-diciembre 2014, 767-784, ISSN: 0018-215X, doi: 10.3989/hs.2014.068 
Y la Figura de este modo aislada se convierte de una Imagen, en un Icono». ${ }^{6} \mathrm{Y}$ esto es muy importante tenerlo en cuenta para Tavener. La sensación sonora que provoca Tavener es figural e imaginativa, por ejemplo, es cosa de pensar en su pieza para violoncelo solista y orquesta de cuerdas The Protecting Veil (1998), donde sonoridad e iconografía van de la mano; la sonoridad va generando el Icono del manto de la virgen para los griegos y creyentes en momentos de penuria (más allá del momento histórico frente a los turcos, propiamente tal). Y en este sentido, el conocimiento de las tradiciones del canto y del sonido, en el ritual religioso, ha sido esencial para un compositor que quiere entrar de forma creativa en el aspecto musical de una religiosa tradición ortodoxa cristiana, en un territorio ya determinado. Este canto sonoro que está entre la comunicación musical espontánea y la celebración de la divina liturgia, ciertamente está más enraizado en las tradiciones cristianas del canto haciendo de la escritura el objeto como se compone y sin limitarse sólo a su aparición. En el caso de la obra que mencionamos, el acorde que se despliega al principio de la obra, aquel acorde de Fa mayor con séptima y sexta agregada no sólo se constituye en ese Icono sonoro en donde la vela le otorga la luz a la imagen y la vibración análogamente le otorga el cuerpo al sonido, sino que los batimentos de la cuerda en vibración en el rozar de los sonidos agregados a la antigua triada de la tradición clásica, le otorgan ese cuerpo sonoro que hace que sea asunto de una luminosidad territorializada ahora como acorde del velo protector, es una imagen sonoro que desde su vibración materializa el cuerpo del Icono en imagen.

Más bien, el compositor es la expresión sonora de esa creación, siendo él, un artesano de la misma manera que un pintor de íconos (como Andrei Rublev) o de una catedral, un fabricante de vitrales o todo trabajo cuyo fin se convierte en una mayor fuerza expresiva de la trascendencia pero en la inmanencia misma de las texturas materiales o estofas y, en este caso, de las estofas sonoras. Deleuze lo indica de la siguiente forma:

Cuando la música levanta su sistema sonoro y su órgano polivalente, el oído, se dirige a cualquier cosa menos a la realidad material del cuerpo, y les otorga a las entidades más espirituales un cuerpo desencarnado, desmaterializado: 'los golpes de timbales de Réquiem son alados, majestuosos, divinos de un ser que, para recuperar las mismas palabras de Stendhal, seguramente tiene relaciones con el otro mundo...'?

Son desde estas estofas sonoras que siempre indican el otro mundo es donde se agencia lo otro (la Figura musical) y se abre la realidad a lo inefable. Tavener sabe, como pocos, que en su composición, en tanto lógica de la sensación sonora,

\footnotetext{
${ }^{6}$ Ibídem, 14.

${ }^{7}$ Marcel Moré, Le dieu Mozart et le monde des oiseaux : 47. Paris: Gallimard, citado en Deleuze, G. 2002: 61 .
} 
acontece y se expresa una ontología corporal de la trascendencia. Y eso es lo que debemos ver a la luz de la filosofía de Deleuze.

¿Qué hay en esta filosofía que nos permite repensar de modo más adecuado lo que acontece en la obra de Tavener? Lo que se da es, como se ha visto, una filosofía del carácter físico de la realidad ${ }^{8} \mathrm{y}$, a la vez, una filosofía que expresa la lógica de la sensación. ${ }^{9}$ Esto es, en esta filosofía se da un cartografiar la experiencia de la sensación en el mundo mismo. Cuerpo y mundo se co-pertenecen. ${ }^{10}$ A veces puede parecer algo menor para un filósofo dedicarse al estudio serio y acabado del tema de la sensación. Pero desde los griegos en adelante, y esto es fundamental para entender el arte de Tavener (tan cercano a los griegos al punto de su conversión del presbiterianismo a la ortodoxia), las filosofías han dicho lo que es la sensación y se han movido en el ámbito de las sensaciones pero de un modo objetivista, positivista y externo. Y este decir ha sido de distinta índole. A veces nos han marcado, definido, limitado, atrofiado lo que es eso que somos nosotros mismos en lo más propio de nuestro ser en tanto que cuerpos en el mundo. Incluso hay ciertas filosofías que han querido negar el cuerpo en su carácter potenciador o volverlo en un mero momento residual y negativo del hombre. Pero así y todo el cuerpo ha estado más presente que nunca; ${ }^{11}$ de allí la necesidad de personas como Freud en un momento determinado de Europa. ${ }^{12}$

Si pensamos, por nombrar algunos, en Demócrito, Epicuro, Lucrecio, Spinoza, Nietzsche, etc. no dudaríamos en asociarlos al tema del cuerpo, ${ }^{13}$ la materia, las sensaciones y es muy probable que coronaríamos este gran horizonte de pensamiento con el filósofo francés Gilles Deleuze (1925-1995), pero en España ha estado (y es pertinente nombrarlo aquí para unos lectores hispano parlantes), entre otros y de modo más solitario, Xavier Zubiri (1898-1983) pensando, bastante a contracorriente por décadas, lo que es el cuerpo, el sentir, las impresiones y ha generado una nueva fenomenología del cuerpo, la cual él llama «noología», pues ya no se trata de ningún objeto que se da a la conciencia dejando de lado todo su carácter físico (como lo típico de la fenomenología husserliana), sino todo lo contrario; es la cosa misma la que se impone en su

\footnotetext{
${ }^{8}$ Espinoza, R. 2006. Realidad y tiempo en Zubiri: 384. Granada: Comares.

${ }^{9}$ Espinoza, R. 2007. «Deleuze y Zubiri...en torno a una lógica de la impresión» en, Contrastes XII: 93-112.

${ }^{10}$ Ascorra, P.; Espinoza, R.; Vargas, E. 2013. «Realidad y actualidad. Una primera aproximación al tema del cuerpo», en, Arbor Vol 189-170.

${ }^{11}$ Ascorra, P.; Espinoza, R. 2011. «Cuerpo y alma en Zubiri...un problema filosófico-teológico» en, Pensamiento 67.

${ }^{12}$ Cabrera, V.; Espinoza, R. 2008. «El Freud de Derrida. La deconstrucción más allá del principio del placer» en, Konvergencias 19.

${ }_{13}^{13}$ Ascorra, P.; Espinoza R.; Vargas, E. 2012, «Nietzsche y la concepción de naturaleza como cuerpo», ALPHA 34.
}

Hispania Sacra, LXVI

134, julio-diciembre 2014, 767-784, ISSN: 0018-215X, doi: 10.3989/hs.2014.068 
propio carácter físico ${ }^{14}$ a la aprehensión humana). En este escrito nos sumergiremos brevemente en Deleuze (porque es nuestro autor principal) para indicar cómo se da el pensamiento del cuerpo y cuál es el alcance de éste para poder dar mayor comprensión a la obra sonora de Tavener. Tengamos presente estos dos textos de nuestros pensadores. Sin embargo, también citaremos a Zubiri porque está en una línea, en este tema, semejante a Deleuze y el filósofo español se expresa de un modo mucho más claro para nosotros. Zubiri es bastante claro en su Inteligencia sentiente cuando nos señala de modo rotundo que:

Las cualidades sensibles son ante todo impresiones nuestras. Y es ahora cuando hay que recordar que la impresión tiene un momento de afección del sentiente y un momento de alteridad de lo sentido... Aquellos dos momentos no pueden dislocarse. Impresión no es sólo afección, sino presentación de algo ‘otro’ en afección: color, sonido, sabor, etc. Por tanto que las cualidades sensibles sean impresiones nuestras significa que en el momento impresivo nos es presente algo otro. ${ }^{15}$

Y Deleuze en una misma línea, y además en años similares que el pensador español, recalca de forma simple que:

«La sensación tiene una cara vuelta hacia el sujeto (el sistema nervioso, el movimiento vital, el 'instinto', el 'temperamento', todo un vocabulario común al naturalismo y a Cézanne), y una cara vuelta hacia el objeto (el 'hecho', el lugar, el acontecimiento). O, más bien, no tiene del todo caras, es las dos caras, es las dos cosas indisolublemente, es ser-en-el-mundo, como dicen los fenomenólogos: a la vez devengo en la sensación y algo ocurre por la sensación, lo uno por lo otro, lo uno en lo otro». ${ }^{16}$

En ambos textos se da algo fundamental para entender la música de Tavener, esto es, ese cierto carácter fenomenológico sensorial donde el sujeto y el objeto se co-constituyen, se co-actualizan, se co-pertenecen. El mismo Tavener habla así de su trabajo en torno a la sensación sonora. Con esta orientación, el compositor británico, se permite percibir el sonido en su forma más primordial, puede empezar a darse cuenta del valor sagrado de nuevos sonidos. En una carta a un joven compositor de la Academia de Música de Londres, donde era profesor de Composición en residencia, escribió:

Vivimos en una época en que absolutamente cualquier tipo de conocimiento académico de la música ya no es útil. El compositor tiene que crear para cada una de sus obras una forma de darse cuenta de la conexión de los sonidos con la idea en primer lugar, la delimitación de lo que en ese sistema es el suyo y lo que

${ }^{14}$ «Físico y real, en sentido estricto, son sinónimos». Zubiri, X. 1962. Sobre la esencia: 12. Madrid: Sociedad de Estudios y Publicaciones.

${ }^{15}$ Zubiri, X. 1980. Inteligencia sentiente: 150. Madrid: Alianza.

${ }^{16}$ Deleuze, G. 2002: 41. 
es particular a la composición que está realizando en ese momento. No sólo hay que tener cuidado para ver la evolución interna de su lenguaje, sino también lo que el lenguaje particular, se debe utilizar para cada composición. ¿Cómo podemos recibir el flujo de datos de sonido o capturarlos si no es nuestro problema? Nuestro trabajo consiste en mantener un silencio interior y entrar en contacto y realizar la visión interna de las relaciones de sonido en forma concreta. ${ }^{17}$

El pensamiento zubiriano desde su etapa final (lo que él llama «noología») ha trabajado el tema del cuerpo desde varios ángulos distintos, aquí nos interesa ese vértice noológico anterior a cualquier «representación», ${ }^{18}$ a cualquier «organización» $\mathrm{o}$ «figuración» de lo que sea el cuerpo, ${ }^{19}$ pero no cualquier cuerpo sino el cuerpo humano; se trata de pensar el cuerpo desde un «prius» en dominancia con respecto de figuraciones, relatos, rostros, narraciones, teorías, hermenéuticas, etc. pues de esta manera podremos sumergirnos en el territorio material sonoro de Tavener; es lo que Deleuze llama radicalmente, siguiendo a Artaud, un «cuerpo sin órganos»:

Las máquinas deseantes no forman un organismo; pero en el seno de esta producción, en su producción misma, el cuerpo sufre por ser organizado de este modo, por no tener otra organización, o por no tener ninguna organización. 'Una parada incomprensible y por completo recta' en medio del proceso, como tercer tiempo: 'Ni boca. Ni lengua. Ni dientes. Ni laringe. Ni esófago. Ni vientre. Ni ano'. Los autómatas de detienen y dejan subir la masa inorganizada que articulaban. El cuerpo lleno sin órganos es lo improductivo, lo estéril, lo engendrado, lo inconsumible. Antonin Artaud lo descubrió, allí donde estaba, sin forma y $\sin$ rostro. ${ }^{20}$

En el cuerpo sin órganos del sonido es desde donde debemos entrar en el territorio sonoro. Es un territorio de presencia, de actualidad sonora y meramente sonora la que acontece en ese modo de componer lo sacro. En el otro extremo, se encuentra el desarrollo de la música de formas y temas (de organizaciones diría Deleuze) que alcanzó su punto culmine con las obras de Mozart o Mahler. En el aspecto más puro de su construcción o de su forma de ser pensada, el sonido está libre de cualquier elemento abstracto religioso y arraigado por completo en el más puro sentido de las formas musicales heredadas del renacimiento. No obstante, en Tavener, el mundo sonoro que es capaz de recomponer

${ }^{17}$ Tavener, J.; Keeble, B. (Eds). 1999. The music of silence: a composer's testament: 95. Londres: Faber \& Faber.

${ }^{18}$ Espinoza, R. 2009. «Deleuze: Leibniz...en torno a los pliegues» en, Aurora 21.28.

19 «La pintura debe arrancar la Figura de lo figurativo», Deleuze, G. 2002:19). Y «... los paisajes de Bacon son la preparación de lo que aparecerá más tarde como un conjunto de concisas 'marcas libres involuntarias' que rayan el lienzo, trazos asignificantes despojados de función ilustrativa o narrativa» (Deleuze, G. 2002: 16).

${ }^{20}$ Deleuze, G.; Guattari, F. 1973. El Antiedipo. Capitalismo y esquizofrenia: 17. Barcelona: Seix Barral.

Hispania Sacra, LXVI

134, julio-diciembre 2014, 767-784, ISSN: 0018-215X, doi: 10.3989/hs.2014.068 
y de colocar en sus obras, puede permitir que los auditores alcancen un estado psíquico en el que son capaces de percibir las estructuras primarias de las formas posteriores de sonido sobre la cual derivarán. Después de Haydn y Mozart, la realización progresiva de la música pura comienza a desaparecer. La música de Tavener es eminentemente expresiva y está más allá de narrativas o encargos. Aunque se mueva en cierta religiosidad, su propia sacralidad es asignificante y, por ende, expresiva. No busca ser n música cerebral, esto es, abstracta, ni tampoco música de historias, sino que es música del cuerpo en su carácter expresivo sonoro. Todo se juega en la materialidad misma del elemento sonoro.

Y por eso en Tavener es anterior la figura de la presencial actual sonora a cualquier estructuración y conceptualización del sonido ya sea cerebral (abstracta) como meramente edificante y narrativa de un cuerpo organizado y enclasado en el dispositivo de turno socio-político. El sonido es presencia sonora actual y como dice Zubiri: «... el cuerpo transciende de toda integración: el cuerpo es personal pero lo es formal y precisamente no como organismo ni como sistema solidario, sino como principio de actualidad». ${ }^{21}$ Pues anterior al rostro, a la figuración, a la narración, a la presencia, a la institución, al compás y la composición tenemos ese hecho radical que fluye inexorablemente: el devenir del cuerpo, en este caso del cuerpo sonoro en su mero ser como sensación. Y de esto hablaremos en breve en este escrito.

II

¿Es posible «leer» entrecruzadamente a Deleuze (y Zubiri) y Tavener (o Poleva en la actualidad)? Aunque parezca tarea condenada al fracaso lo intentaremos respecto del problema del sentir y la sensación. Para un pensador, como Deleuze, que ya no cree del todo en la Fenomenología meramente académica (por eso nosotros preferimos la de Zubiri; que es una fenomenología de lo físico de la realidad), pero que ha tenido como maestros, entre otros a Sartre y a Merleau-Ponty y ha sido uno de los grandes lectores y renovadores del pensamiento de Bergson, del pensamiento de Nietzsche, amigo de Foucault, la filosofía ya no tiene nada que ver con metodologías neutralizadoras, de reducciones, de abstracción; no solamente llega tarde una reducción trascendental de Husserl (Deleuze a veces trata peyorativamente a la fenomenología como «hipótesis fenomenológica»), sino que la misma reducción eidética falsifica el hecho de la materia, del cuerpo, el hecho mismo del sentir, del ver, de la relación que se da, por ejemplo en la pintura, entre un Ojo ante un Cuadro $^{22}$ tal o cual (lo mismo

\footnotetext{
${ }^{21}$ Zubiri, X. 1980: 213.

$22 \ll .$. la pintura es quien descubre la realidad material del cuerpo, con su sistema líneas-colores, y su órgano polivalente, el ojo. 'Nuestro ojo insaciable y en celo', decía Gauguin. La aventura de la pintura consiste en que sea solamente el ojo quien hay podido encargarse de la existencia material, de
} 
con un Film, con una Novela, con una Pieza teatral, con una Sonata, con una Teoría científica, con un Horizonte filosófico, con un Hombre, con un Pueblo, con un Coro, etc.). No hay organización posible, lenguaje posible, ni filosofía posible, ni teoría posible que dé cuenta de ese simple hecho: oír, por ejemplo, un coro de la obra de Tavener (UK), o de Meredith Monk (USA), o de Victoria Poleva (Ucrania), etc. Para Deleuze el marxismo, el estructuralismo, el psicoanálisis, las teorías estéticas, las políticas, las éticas, las religiosas, epistemológicas, metafísicas en realidad no saben qué hacer con el hecho mismo del cuerpo, de la sensación, de la impresión. Y de allí el método de Deleuze de filosofar: su Lógica en «taxonómica natural». Es una Lógica que se organiza con distintos contenidos, es una Lógica de tal o cual cosa, de tal o cual pliegue. Por ejemplo, Lógica (sentido), Lógica (cine), Lógica (sensación), Lógica (Proust), Lógica (Foucault), etc. Y ¿qué se entiende por Lógica en este pensamiento de Deleuze? ¿Existe algún rasgo de negatividad en ella? ¡No la hay!.23

Aquí podemos ver la impronta hegeliana del pensamiento de Deleuze (impronta que siempre rechazó radicalmente; Deleuze se sentía como un «parricida» respecto de Hegel $;{ }^{24}$ en todo caso, un asesinato «necesario»), impronta que le viene de las ya clásicas «lecturas» hegelianas que realizó en París Jean Hyppolite (otro de los maestros de Deleuze). Pero es una lógica que no pretende ser negativa, sino afirmativa como la Lógica de Nietzsche; es una Lógica que dice ¡Sí!

\section{III}

En su contexto social, Tavener era un compositor de música sacra escrita (que puede o no corresponder con la escritura de la música litúrgica), en una sociedad totalmente laica en su orientación, y por ello Tavener miraba hacia atrás y trataba de recuperar el paraíso perdido y, además, no olvidemos que ya en 1977 se vuelve ortodoxo ruso (incluso vivía en Grecia). Él no estaba por reinventar una música falsamente paradisíaca, sino por la creación de un

\footnotetext{
la presencia material: incluso para una manzana». (Deleuze, G. 2002: 61). Lo mismo debemos decir, desde una lógica de a sensación, para la música, el sonido y el oído.

${ }^{23}$ Zubiri, desde muy joven (1935), en la misma línea de Deleuze y mucho antes que él, ya nos decía lo siguiente a cómo se debe entender una verdadera lógica: «... la realidad de la verdad nos manifiesta realmente la verdad de una realidad sentida en nuestro sentir. Y el problema será ahora escindir dentro de esta verdad de la realidad, la cosa realmente verdadera, o la realidad verdadera de la cosa... Junto con plantear el problema citado, para el cual hará falta no sólo una lógica de los principios, sino una lógica de la realidad. ¿Cómo asegurar el sentir la posesión esciente de la realidad?». Zubiri, X., 2002. «Filosofía y metafísica» en, Zubiri, Sobre el problema de la filosofía y otros escritos (1932-1944): 202. Madrid: Alianza. Y esto es fundamental para nuestro estudio de Tavener.

${ }^{24}$ Véase, Espinoza, R. 2012. «Repensando a Deleuze y el 'Acontecimiento' desde lo 'Lógico' de la Wissenschaft der Logik de Hegel... En torno al devenir cosa» en, Espinoza, R. (Ed). Hegel. La transformación de los espacios sociales:155. Concón: Midas.
}

Hispania Sacra, LXVI

134, julio-diciembre 2014, 767-784, ISSN: 0018-215X, doi: 10.3989/hs.2014.068 
nuevo sentido musical utilizando como bloque de construcción los elementos sonoros del canto religioso antiguo, específicamente aquellos rusos y griegos desde la propia materialidad del ritual bizantino, de vastas líneas melódicas de gran belleza, a menudo iconos, en donde su memoria (su «auralidad acústica» musical) se mantiene e informa a su música. Tal «auralidad» del carácter expresivo físico de su música icónica busca realmente que acontezca la sensación corporal sonora, sensación donde sujeto y objeto se funden en la inmediatez. Y así su música genera el órgano del oír (y también del ver), desde el cual se articulan tanto sensación sonora del sonido como sensación sonora del oyente. En una fase bastante temprana de su obra tenía una forma de llegar a estados muy creativos en silencio puro y capturó estas obras en papel como visiones completamente psíquicas que él describe como «visión auditiva».

$\mathrm{Y}$ en este mutuo co-pertenecerse se va dando tanta la realidad sonora de lo otro, de otro que se siente en el ritual como cuerpo Otro que nos acontece y, a la vez, se da la realidad del oyente que somos como cuerpo. Tanto realidad sonora como cuerpo emergen del acontecer de la música de Tavener. Las obras son así, una yuxtaposición de sonidos que se caracterizan por una síntesis de la forma de la antigua praxis ortodoxa y los valores de regularidad rítmica en un continuo dinámico propio de la música polifónica del hoy mirando al ayer. Como ejemplo de ello es interesante escuchar la obra «Hymns of Paradise» (1992) para bajo solo, voces de niños y seis violines. Primero, la construcción de un cuerpo sonoro basado en el acoplamiento de los violines (como si fueran ondas) en su registro agudo y el característico batimento del vibrato de la voz femenina que, atrapadas las voces en los violines en su vibrato y viceversa, se hace cuerpo un nuevo sentido del batimento sonoro basado en la superposición de capas y pliegues que fracturan la tradición del plano melódico, plano armónico, plano instrumental, entre otros, dejando en este caso al descubierto un nuevo cuerpo que emerge desde algún lugar aún no humanizado, sino basado en una ley física amarrada a una sentencia divina. Esta pieza con texto de San Efrén el Sirio, a quien se le considera uno de los importantes poetas de la época patrística es un himno que entra en la continuad del minimalismo sacro basado en una concepción de la velocidad, en una notoria sensación de estar fuera del tiempo y el espacio, es el paraíso desde la escatología, y el paraíso que deviene grito en el coro de manera gloriosa en la resurrección final, como puede sentirse hacia el final de la obra en la exultación de la palabra Paraíso.

Las formas elementales son así creadas una y otra vez representando los valores anteriores de la Cristiandad. El sonido físico, en calidad de valores de un sonido puro, contiene el potencial activo de los niveles anteriores. Si las relaciones de los tres niveles están correctamente establecidas y la visión primaria expresada, una fuerza mayor se genera no sólo en el sonido, sino también en la «visión auditiva» (es el Ikono tal como también lo ve Deleuze). En tal estado de 
los sonidos, no se puede considerar como música, sino como patrones de sonido que están directamente vinculados con el antecedente, los niveles más altos y por lo tanto, superior en su carácter expresivo (de allí que se pueda pensar este modo del acontecer sonoro como un cierto acoplamiento de los sonidos). En Tavener se da formalmente una lógica de la sensación, al estilo como Deleuze luego la formula conceptualmente en su filosofía.

Por lo tanto, lo sacro se manifiesta a Tavener, en principio, en una lógica de la sensación sonora de timbres instrumentales y de vibraciones de una hermosa música polifónica. Para Tavener el problema de escribir su obra nunca fue un problema de la Academia, sino simplemente un problema de profunda sinceridad hacia su propia persona y hacia su fe, de esto tiene la facultad de contemplar las estructuras internas de los sonidos que iba descubriendo desde la mirada permanente de los ikonos, como también de las resonancias que se forman en la catedrales en las cuales practicaba la composición. Junto a ello, las formas de entonación bizantinas, las ornamentaciones, los pedales y una serie de recursos propios de la Iglesia Ortodoxa le fue suministrando la forma de mirar la nueva Academia, a la cual el accedía por convicción. Estos elementos de la composición de Tavener son parte de sus materiales para confeccionar su lógica de la sensación sonora sacra.

De allí al reconocimiento de la sensación-voz, del devenir voz; voz como el instrumento «asignificante» por excelencia. Como dicen Deleuze y Guattari en Mil mesetas: «La voz precede al rostro, lo forma un instante, y le sobrevive al adquirir cada vez mayor velocidad, a condición de ser inarticulada a-significante, a-subjetiva». ${ }^{25} \mathrm{Y}$ de allí luego acontece la narrativa y el mensaje de la fe y así su arte sonoro quedaría impregnado, creemos, realmente como un arte de la sensación sonora en devenir voz, siempre y vibración que permite, luego para el creyente, el carácter de salida a otro mundo, al mundo de Dios.

Al componer su música, tiene que escribir desde su cuerpo y debe ser honesto con él. En una aproximación directa a su pensamiento, indica: «Un compositor de música sacra es sólo un mediador, un intermediario y un instrumento para comunicar esta verdad. Mi música es un comentario de la obra de la creación». ${ }^{26}$ Allí surge, en su trabajo, la constante repetición de su lógica de la sensación musical y las palabras, en el coro, van reteniendo el ritmo de los acontecimientos, alargando el tiempo, suspendido y contemplado. En su modo de componer, su diagrama musical, tiene la iteración y en tanto tal la repetición; el sonido vocal o de un cello va aconteciendo en tanto bucles de repetición, que vuelven en diferencia. Es el eterno retorno de la diferencia tan propio de Nietzsche y clave

\footnotetext{
${ }^{25}$ Deleuze, G.; Guattari, F. 2000: 314.

${ }^{26}$ Tavener, J.; Mother, T. 1994. Ikons Meditations in Words and Music: 81. London: Harper Collins Publishers, 1994.
}

Hispania Sacra, LXVI

134, julio-diciembre 2014, 767-784, ISSN: 0018-215X, doi: 10.3989/hs.2014.068 
hermenéutica de Deleuze. Repetición en la diferencia. ${ }^{27}$ En el plano de inmanencia de las estofas materiales sensitivas se va dando la intensidad y la vibración: «De manera que la sensación no es cualitativa ni está cuantificada, no tiene más que una realidad intensiva que ya no determina en ella datos representativos, sino variaciones alotrópicas. La sensación es vibración». ${ }^{28}$ La sensación sonora es vibración y lo que sabe Deleuze y Zubiri que tal sensación sonora en intensidad vibratoria se impone físicamente al hombre, en todo su cuerpo y allí radica el arte mismo de Tavener en su manifestación física que nos seduce y provoca (incluso más allá de una fe determinada y de algún cuento que se nos narre de modo histórico). En cierta forma, nos vuelve cuerpo en la sonoridad misma de la realidad. La repetición de la música da una sensación de estancamiento, de estar suspendido en el tiempo. «El tiempo y la eternidad están conectados». ${ }^{29}$ «Este instante y la eternidad están luchando dentro de nosotros. Y ésta es la causa de todas nuestras contradicciones, nuestra obstinación, nuestra mente estrecha, nuestra fe y nuestro dolor». ${ }^{30}$ Lo que convencionalmente llamamos música sacra minimal, como la de Tavener, es una evolución de los fenómenos del sonido que se originaron con los «encantamientos», como los cantos rituales de los pueblos no europeos o el canto gregoriano de la Cristiandad occidental. Su sensación más fuerte era despertar ciertos estados psíquicos en los seres humanos, lo que permitía que su noción de audición se expandiera más allá de su marco conceptual tradicional y representativo. Si estos «encantamientos» provenían de la naturaleza de la arquitectura del espacio sacro, a continuación las vibraciones producidas, colaboran con la inducción a un estado que ya no era puramente emocional (ni subjetivo) en el sentido usual, sino puramente físico en el sentido de la pureza del sonido y su condición de elemento abstracto, esto es, elemento que se ha elevado de la representación y significación mimética; por eso es «asignificante».

Por esta razón, que el tiempo en la música de Tavener es parte de un momento «aiónico» como diría Deleuze (tiempo «modal» en términos de Zubiri), el tiempo eterno e imperecedero, un tiempo sin principio ni fin, un tiempo esférico que es sentido en las cosas mismas, en las sensaciones: «El hombre físicamente real tiene que hacer su vida en la cotidianidad de su existencia en el transcurrir de sus días... La realidad humana cobra sentido para sí misma en su temporalización como yo

\footnotetext{
${ }^{27}$ «La lógica nietzscheana es siempre afirmativa (ese es el enigma de Ariadna y del eterno retorno dicho por el último Nietzsche), es corporalmente afirmativa y de allí que la negatividad del «no» ya no sea sentida como algo «meramente negativo o dialéctico», doloroso, pesado, moderno, kantiano, sino como parte necesaria del «sí» afirmativo. Estamos ante el Untergang (ocaso) en su carácter verbal untergehen (ir hacia abajo, descender, hundirse) y su Übergang (tránsito) en su respectivo übergehen (ir hacia arriba, ascender, transitar) que abre la obra Así habló Zaratustra y el caminar único que emprende el personaje de Zaratustra; su única meta, su felicidad». Ascorra, P.; Espinoza R.; Vargas, E. 2012: 10).

${ }^{28}$ Deleuze, G. 2002: 51.

${ }^{29}$ Tavener, J.; Keeble, B.1999: 66.

${ }^{30}$ Haydon, G. 1995. John Tavener: Glimpses of Paradise: 148. London: Orion.
} 
que está en el mundo». ${ }^{31} \mathrm{Y}$ de ese tiempo es posible luego ir hacia otro tiempo, a un tiempo sagrado, un momento de euforia mística, un tiempo de oración, un tiempo revelado y de libertad. Pero el tiempo mismo surge y emerge del plano de inmanencia de la sensación y de allí que el artista necesite sumergirse con todo ya en su oído, ya en su ojo, ya en los colores, ya en los sonidos y sus vibraciones para que se pueda ir amplificando y expandiendo la realidad. Tavener en la música, como un Cézanne en pintura, va expresando tanto al hombre como su mundo desde la corporalidad de la sensación sonora en intensidad vibratoria y en repetición diferenciante.

Esta lógica de la sensación sonora sentida por el hombre produce una aparente dificultad para escuchar la música de Tavener, pues el mismo autor británico reconoce que - a su juicio - «existe un nivel de impureza del alma que permita escuchar el sonido de la eternidad»..$^{32}$ Tal impureza radica en no poder dejar que la sensación haga lo suyo, ya que estamos constantemente perforados y mediatizados por una sociedad (una cultura representativa y significada) que ya no oye el sonido en su devenir y lo tiene a priori sobre codificado desde un modo presente que se actualiza. El cuerpo domado a través del control de la sociedad impide ya al parecer poder escuchar la sensación sonora y lo mismo pasa con la pintura y todas las artes y en ello el cuerpo mismo ahora está domesticado. Así, es posible hoy escuchar cierta música occidental de mercado, debida fundamentalmente a que gran parte de ella es fabricada para halagar al oído y que esa sensación simplemente sea reproductora de una narrativa, de una figuración con rostro predeterminado, esto es, el modelo tardo capitalista de un arte representativo al servicio del operador de turno, no es el arte «asignificante».

Por eso la música Occidental parece, al menos superficialmente más «hermosa», pues está más cerca de un «kitsch» y en este sentido, y por ello, mucho más fácil para escuchar. Esta música requiere otro tipo de atención. El oyente tiene que entregarse a la música de una manera totalmente diferente, se debe entregar a la sensación física del sonido sentido con el cuerpo. Para Tavener, decir que la música existe para el bien de un plano superior, es arriesgarse a ofender la comprensión de algunas personas, porque el público de hoy no está en sintonía con una forma existencial de vida, que busca algo por encima de la realidad, algo otro. Deleuze explica muy bien este rasgo «esquizofrénico» de la sensación sonora en «Del Ritornelo» en Mil mesetas:

En líneas generales, se puede decir que la música está en conexión con un filum maquínico infinitamente más poderoso que el de la pintura: línea de

\footnotetext{
${ }^{31}$ Espinoza, R. 2006: 351.

${ }^{32}$ Tavener, J.; Keeble, B. 1999: 113.
}

Hispania Sacra, LXVI

134, julio-diciembre 2014, 767-784, ISSN: 0018-215X, doi: 10.3989/hs.2014.068 
presión selectiva. Por eso el músico no tiene con el pueblo, con las máquinas, con los poderes establecidos, la misma relación que el pintor. ${ }^{33}$

En contraste al narcisismo actual, aparece la música de Tavener principalmente expresiva meditativa (abstracta), pero es un tipo de expresividad en la sonoridad material misma (parecido en la pintura a Rothko), donde la sonoridad se libera de lo empírico, sin embargo, siempre desde un tema determinado (por ejemplo, el velo protector de la virgen) y así se va liberando el trabajo de Tavener de la composición representativa barroca, clásica, etc. Y es desde este tipo de producción estética en la abstracción expresiva de la materialidad, donde la obra musical permite múltiples rituales y la serena devoción por parte de los creyentes. Es una expresión, pero del tipo corporal, no cerebral, esto es, no es la vía de la abstracción al estilo Malevich, sino al estilo Pollock, Rothko, etc. Es abstracción expresiva corporal en la sensación sonora de un tema determinado, y es ahí donde se da la fuga propiamente tal del tema. Y en ello acontece, eso que llama Deleuze, el carácter «esquizoide» de la música que se abre a lo otro.

Por esto no podemos olvidar, que en la música se da ese devenir a la totalidad, pero que emerge desde la sensación misma física del sonido; tal sonido emerge y se nos impone en nuestro carácter mismo aprehensivo. En esto Deleuze lo dicen casi de la misma forma:

... el sonido nos invade, nos empuja, nos arrastra, nos atraviesa. Abandona la tierra, pero tanto para hacernos caer en un agujero negro como para abrirnos a un cosmos. Nos da deseos de morir. Al tener la mayor fuerza de desterritorialización, también efectúa las reterritorializaciones más masivas, más embrutecedoras, más redundantes. Éxtasis o hipótesis. No se mueve a un pueblo con colores. ${ }^{34}$

Y esta descripción sentiente del sonido se expresa en la obra de Tavener, de allí lo que decíamos al comienzo, que el sonido en su obra tenga carácter Icono. Es un sonido iluminador y acotado, que se eleva en la sensación misma y en ello eleva al que oye. Se da, como se dice en el arte sacro, un sentido del espacio y del tiempo de inmutable «glorificación»; espacio-tiempo característico de los Iconos, que son espejos para oír y ver el mundo eterno, esto es, las piezas musicales de Tavener en su carácter icónico se asemeja a los redondeles de las pinturas de Bacon (tan estudiados por Deleuze). En esas acotaciones y marcos, la Figura, el Icono sonoro da de sí la trascendencia, pero no es por la representativo ni significante del tema narrativo, sino por la sensación sonora misma en su carácter de Icono y de vibración envolvente y expresiva del todo cósmico: «Si hay algo que deseo hacer en mi música - dice Tavener-, esto es de algún modo

\footnotetext{
${ }^{33}$ Deleuze, G.; Guattari, F. 2000: 351.

${ }^{34}$ Ídem.
} 
redescubrir el Paraíso perdido». ${ }^{35}$ De eso se trata, de «re-descubrir el Paraíso» en la sonoridad icónica misma de la vibración y que como tal se da una cierta minimalidad, ya del instrumento, ya de la voz en tanto instrumento, minimalidad, como la hemos visto, que es siempre «eterno retornante», esto es, en el instante de la vida en su transcurrir. Tavener, es interesante, porque rechaza los valores normalmente asociados con la música contemporánea o de vanguardia. $\mathrm{El}$ «minimalismo sacro» es a la música lo que la espiritualidad contemplativa a la oración. Para la mayoría de nosotros, la oración consiste en hacer frente a nuestras palabras a un Dios determinado (representativo y significado), pero a la oración contemplativa, es escuchar en silencio receptivo (a un Dios «asignificante»). Considerando que en la música tradicional que espera oír el desarrollo de ideas musicales avanzando hacia una conclusión climática, esta música parece ir a ninguna parte, y esto es intencional. El objetivo es la contemplación. La música es meditación, hipnótica y repetitiva con una suavidad como en la tradición cristiana de centrar una oración continua, y que puede repetir una o dos palabras de la Escritura que se elaborará más profundamente en la oración.

Finalmente, tenemos que hacernos cargo de algo fundamental en la obra sacra del compositor británico: el sonido del Ison: «El Ison representa para mí la divina presencia y en la mayoría de los casos lo escribo con ese sentido de eternidad que hace presente a Dios en todas partes, en donde logro encontrar metafísicamente un punto de unión entre el, mi música y la gente». ${ }^{36}$ Para John Tavener, la presencia divina (su Figura diría Deleuze o su actualidad diría Zubiri) en la materialidad sonora del Icono minimal y vibratorio y, por tanto, en algún lugar supone también que en cada momento de su trabajo como compositor escribe esta nota. Esta nota tiene que estar ya que es, como se dijo, expresión de eternidad. Así como en las pinturas de Bacon acontece el orificio, la boca abierta, el grito, aquí se da el Ison como actualización de lo otro en tanto que Otro; otro que no puede no estar presente y co-actualizarse en la sensación sonora misma. Y si nos damos cuenta, el Ison, es como esa luz que aparece en la fotografía de los film de Roberto Rossellini, como Stromboli, Terra di Dio (1950) o Viaggio in Italia (1954), ${ }^{37}$ en donde la luz juega un papel importantísimo como «tierra de Dios», esto es, su figura icónica que se presenta al hombre y al indicar tal presencia siempre en la distancia de la que se está de todo, por estar en la luz, se señala, obviamente por todos, también el «silencio de Dios». Es la luz, el carácter físico «aurático» del sonido icónico en la que acontece todo tipo de sensación sonora.

\footnotetext{
${ }^{35}$ Tavener, J.; Keeble, B. 1999: 99.

${ }^{36}$ Ibídem., p.154.

${ }^{37}$ Espinoza, R. 2006. «'Viaggio nella realtá'...La mirada diáfana del Cristianismo: Rossellini y Zubiri» en, Misceláneas Comillas 64.125.
}

Hispania Sacra, LXVI

134, julio-diciembre 2014, 767-784, ISSN: 0018-215X, doi: 10.3989/hs.2014.068 


\title{
CONCLUSION
}

\begin{abstract}
«Vivimos en una época que no cree que el sonido es capaz de ponernos en contacto con niveles más altos de la realidad» (Tavener y Mother, Ikons Meditations in Words and Music: 85).
\end{abstract}

«Así que estoy en el limbo» (Tavener y Mother, Ikons Meditations in Words and Music: 88$)$.

Tavener ha conducido su música dibujada espiritualmente en el arte ortodoxo griego y ruso como corrientes cristianas. Con ello, ha logrado establecer una ecuación de arte planteada desde el ser que está suspendido en el tiempo, entendiendo por ello, el ritmo de la vida que se revela en esa relación dicotómica de sincronía con la cotidianeidad y que interrumpe la diacronía del mero ritmo del transitar, del cual todos nos vamos adecuando en la búsqueda de una vida más pulsada, más gradual, de inconmensurable belleza, de un goce en la experiencia y en la sensación, que alcanza lo breve de la brevedad, del paso del hombre por su mundo inmanente.

Debe tenerse en cuenta de que la música de la vanguardia no son experimentos cuyo objetivo es ir más allá de la música, sino más bien trata de mantener vivo un sentido de viva experimentación que ha sido deliberadamente conducida por un grupo de compositores en una abierta oposición a otro grupo que aun desea mantener la tradición no solo de la enseñanza de la música, sino también la forma en que esta debe sonar y el sentido de «agradabilidad» que la sociedad espera consumir. Tavener logra recomponer el escenario de su entorno inglés y sacro diciendo «que los compositores ya no pueden crear música alineándose con ninguna de las escuelas estéticas de compositores establecidas y que tienen que abandonar la idea de escribir la música como tal y comenzar a pensar en un fenómeno del sonido que va más allá de la música». ${ }^{38}$

De eso se trata, de pensar ese fenómeno del sonido desde una lógica de la sensación sonora; tal lógica permite darnos cuenta de cómo se nos impone el sonido y cómo, en ello, se indica una dimensión material de la trascendencia, una que acontece en la expresión abstracta de la voz, por ejemplo, de un coro de Tavener.

\section{BiBLIOGRAFIA}

Ascorra, P. y R. Espinoza. «Cuerpo y alma en Zubiri...un problema filosóficoteológico.» Pensamiento 67 (2011): 1061-1075.

Ascorra, P., R. Espinoza y E. Vargas. «Nietzsche y la concepción de naturaleza como cuerpo.» ALPHA 34 (2012): 95-116.

\footnotetext{
${ }^{38}$ Tavener, J.; Keeble, B. 1999: 131.
} 
Cabrera, V. y R. Espinoza. «El Freud de Derrida. La deconstrucción más allá del principio del placer.» Konvergencias 19 (2008).

Deleuze, G. Francis Bacon._Lógica_de la sensación. Paris: La Différence, 1981.

Deleuze, G. y F. Guattari. El Antiedipo. Capitalismo y esquizofrenia. Barcelona: Seix Barral, 1973.

- Mil Mesetas. Capitalismo y esquizofrenia. Valencia: Pre-textos, 2000.

Deleuze, G. y F. Guattari. «Postulados de la Lingüística.» Deleuze, G. y F. Guattari. Mil_Mesetas. Capitalismo y esquizofrenia. Valencia: Pre-textos, 2000.

Espinoza, R. «Deleuze y Zubiri...en torno a una lógica de la impresión.» Contrastes XII (2007): 93-112.

«Deleuze: Leibniz...en torno a los pliegues.» Aurora 21.28 (2009): 125-139.

Hegel.La transformación de los espacios sociales. Ed. R. Espinoza. Concón: Midas, 2012.

Realidad y tiempo en Zubiri. Granada: Comares, 2006.

«'Viaggio nella realtá'...La mirada diáfana del cristianismo: Rossellini y Zubiri.» Misceláneas Comillas 64.125 (2006): 220-240.

«Zubiri y Husserl. Una crítica desde el carácter físico a la intencionalidad.» Cuadernos Salmantinos de Filosofía XXXIII (2006): 341-366.

Espinoza, R. y J. Nicolás, Zubiri ante Heidegger. Barcelona: Herder, 2008.

Espinoza, R., P. Ascorra y E. Vargas. «Realidad y actualidad. Una primera aproximación al tema del cuerpo.» ARBOR 189-760 (2013).

Haydon, G. John Tavener: Glimpses of Paradise. Ed. Victor Gollancz. London: Orion, 1995.

Tavener, J. y B. (ed.) Keeble. The music of silence: a composer's testament. Faber \& Faber, 1999.

Tavener, J. y T. Mother. Ikons Meditations in Words and Music. London: Harper Collins Publishers, 1994.

Zubiri, X. Inteligencia sentiente. Madrid: Alianza, 1980.

Sobre el problema de la filosofía y otros escritos (1932-1944). Madrid: Alianza, 2002.

Sobre el sentimiento y la volición. Madrid: Alianza, 1993.

Sobre la esencia. Madrid: Sociedad de Estudios y Publicaciones, 1962. 